\title{
RECTITUDO E LIBERTAS EM DE LIBERTATE ARBITRII DE SANTO ANSELMO
}

\author{
José M. Silva Rosa \\ Universidade da Beira Interior - Covilhã
}

... saepe apta interrogatio expedit responsionem, et inepta reddit impeditiorem. ${ }^{1}$

As temáticas da vontade, do livre arbítrio e da liberdade, decisivas para a Antropologia, a Ética, a Filosofia Moral e Política, costumam normalmente ser apreciadas pelo viés da Filosofia Moderna, onde teriam alcançado tematização ímpar de cidadania, mercê da plêiade de reinterpretações filosóficas da Reforma, mais do que mediante os contributos do pensamento medieval.

De há algum tempo a esta parte, porém, numerosos autores vêm sublinhando e mostrando as raízes antigas e medievais - tanto teológicas como filosóficas - de tais problemáticas, como por exemplo Charles Taylor, na obra Sources of the Self: The Making of the Modern Identity ${ }^{2}$, ou Hanah Arendt em The Life of Mind ${ }^{3}$. Significativamente, porém, no que respeita ao segundo volume desta última obra, intitulado Willing, $\mathrm{H}$. Arendt faz uma mais que discutível, secundum nos, selecção de autores medievais, pois apenas acolhe Agostinho, Tomás de Aquino e Duns Escoto, não havendo uma palavra sequer em relação a Santo Anselmo, o qual, todavia, é um autor decisivo (tal como, entre outros, Pedro Abelardo) para uma "história da liberdade". Mas fora Anselmo um autor marginal que não é (e amiúde é nas margens que o novo advém, mormente na Idade Média) e ainda assim o opúsculo De Libertate arbitrii mereceria de

${ }^{1}$ Anselmo de Cantuária, De Casu diaboli, XXVII, 275, 14-15: «... a interrogação conveniente fornece muitas vezes a resposta, enquanto a inepta só a embaraça.»

2 Cambridge University Press, Cambridge, 1989.

3 Vol I, Thinking; Vol. II, Willing, Harcourt Brace Jovanovich, New York, 1978.

Philosophica, 34, Lisboa, 2009, pp. 359-370 
per si renovada a atenção, mesmo que o estudioso seguisse o contestável critério de uma qualquer "via real" de autores ${ }^{4}$.

É certo que os pressupostos da autora tornam-na mais atenta e interessada nas liberdades concretas e na sua aparição visível no mundo, na cidade dos homens (liberdade de movimentos, liberdade para iniciar novos processos, liberdade para falar, para agir, ...) do que em investigar $a$ liberdade transcendental do arbítrio, condição ante-mundana da acção, ainda por cima querendo-se extensível a Deus, aos anjos e aos homens. A investigação de Anselmo que, com certeza $\mathrm{H}$. Arendt não desconhecia, deve ter-lhe aparecido demasiado "escatológica", longe do drama das liberdades concretas na história, in statu isto, lançadas num mundo onde têm que agir e tomar decisões. Os homens só são livres quando agem; nem antes nem depois: eis a tese da autora de The Life of Mind. Será esta a razão por que, a nosso ver, a investigação de Anselmo de Cantuária lhe pode ter aparecido estranha e até mesmo esotérica, e na qual, ao contrário da afirmação de Santo Agostinho: "initium ut esset creatus est homo, ante quem nullus fuit"s, parece não vislumbrar nenhum ponto de inserção na história da liberdade dos filhos dos homens.

A fim de introduzir o tema em apreço, nada melhor que começar com as palavras do próprio Anselmo, no Prefácio a De Veritate, onde, referindo-se ao tríptico de tratados sobre estudo da sacra scriptura ${ }^{6}$ que compusera na forma de pergunta e resposta, enuncia formalmente, com clareza e concisão, as questões que De Libertate arbitrii (escrito entre 1180 e 1185) pretende esclarecer. Diz-nos Anselmo que, neste opúsculo acerca da liberdade do arbitrio, três questões irão ser tratadas: o que ela é; se o homem a tem sempre; e como é que ela se diversifica conforme o

\footnotetext{
4 O pressuposto mais ou menos tácito de uma "via real" de autores tendeu a colocar Anselmo, e o seu estilo interrogativo e mais ou menos aporético, como "precursor" da Escolástica do séc. XIII, de onde finalmente se deveria esperar as "soluções definitivas" dadas por Tomás de Aquino aos temas da liberdade e do livre arbítrio, na sua compaginação com a graça divina. Contra esta visão que "instrumentaliza" Anselmo e o desenraíza do seu contexto, cf. Michel CORBIN, "Introdução", in L'œuvre de saint Anselme de Cantorbéry, Paris, Cerf, Éditions du Cerf, Paris, 1986, vol. II, pp. 181 e ss. (seguimos esta edição bilingue de De libertate arbitrii, nas pp. 205-226, traduzida com o título De la liberté du choix por Rémy de Ravinel, s.j., Introdução e Notas de Michel Corbin).

5 De Civitate Dei, XII, 21.

${ }^{6}$ De Veritate, Praefatio, p. 173, 2: «tres tratactus pertinentes ad studium sacrae scripturae.» Aos referidos De Veritate e De Libertate arbitrii acresce De Casu diaboli. Um quarto tratado, o opúsculo De Grammatico, porque trata de uma introdução à Dialéctica, não emparelha com a trilogia.
} 
homem tem ou não rectitudo voluntatis. Precisa ainda que, neste escrito, quis «mostrar apenas a força natural da vontade para guardar a rectitudo recebida, mas não como para isso lhe era necessária a graça.» ${ }^{7}$

Ora De Libertate arbitrii começa justamente pelo dilema que mais profundamente marcou a antropologia teológica cristã, a começar no Paulo da Carta aos Romanos e da Primeira Carta aos Coríntios, e sobretudo depois do debate entre Agostinho e Pelágio, que é ainda o pano de fundo da investigação de Anselmo ${ }^{8}$.

Com efeito, o fictício interlocutor de Anselmo avança logo de início com o problema, interrogando-o: «Uma vez que o livre arbítrio (liberum arbitrium) parece incompatível com a graça (...), desejo saber exactamente o que é a liberdade do arbítrio (libertas arbitrii $i^{9}$ ) e se sempre a temos.» E acrescenta acto contínuo: é que «se a liberdade do arbítrio consiste em 'poder pecar e não pecar' (posse peccare et non peccare), e se sempre temos em nós este poder, como é que temos por vezes necessidade da graça? Todavia, se não o temos sempre, porque é que o pecado nos é imputado, quando pecamos sem livre arbítrio?» ${ }^{10}$

Este modo de começar in medias res permite a Anselmo, de imediato, deixar clara uma das teses principais do opúsculo: em seu entender, $a$ liberdade do arbitrio não consiste nem, pode consistir, no poder de pecar e não pecar ${ }^{11}$. A razão é evidente para o autor de De Libertate arbitrii,

${ }^{7}$ De Veritate, Praefatio, p. 173: «Alis vero De libertate arbitrii: quid sit, et utrum eam semper habeat homo, et quot sit eius diversitates in habendo vel non habendo rectitudinem voluntatis, ad quam servandam est data creaturae rationali. In quo naturalem tantum fortitudinem voluntatis ad servandam acceptam rectitudinem, non quomodo necessarium ad hoc ipsum illi sit ut gratia subsequatur ostendi.»

8 Alguns pretendem que a esta questão, antes de ser teológica, é mais propriamente cristológica, no sentido do mysterium da unidade das duas naturezas de Cristo, mysterium adensado ao limite, no Horto das Oliveiras (Mt 26, 39), quando Jesus ora, pedindo que não se faça a sua vontade, mas a do Pai: «... et progressus pusillum procidit in faciem suam orans et dicens: ' $\mathrm{mi}$ Pater si possibile est transeat a me calix iste verumtamen non sicut ego volo sed sicut tu'.»”

${ }^{9}$ Rémy de Ravinel traduz sempre a expressão por liberté $d u$ choix; cf. as razões em Michel CorBIN, "Introdução", pp. 186 e ss.

10 De Libertate arbitrii I, 207, 4-6. Tema que já ocupara Agostinho de Hipona, Contra Felix Manichaeum, II, 3: «Esse autem liberum arbitrium, atque inde peccare quemque si velit, non peccare si nolit...»; De Libero arbitrio I, XVI, 35: «Sed quaero utrum ipsum liberum arbitrium, quo peccandi facultatem habere convincimur...»; Contra Julianum, opus imperfectum, I, 78: «Libertas arbitrii, qua a Deo emancipatus homo est, in admittendi peccati et abstinendi a peccato possibilitate consistit.»; 82: «Libertas igitur arbitrii, possibilitas est vel admittendi, vel vitandi peccati...»; De correptione et gratia, I, 12, 33: Non potuit peccare, qui tale habebat liberum arbitrium? (...) Prima ergo libertas voluntatis erat, posse non peccare; novissima erit multo maior, non posse peccare.»

11 De Libertate arbitrii, I, 207, 11-12: «Libertatem arbitrii non puto esse potentiam peccandi et non peccandi.» 
mas de início é colhida pela negativa: se assim não fosse teríamos de concluir, necessariamente, que nem Deus nem os anjos bons, visto que não podem pecar, teriam liberdade de arbítrio - «quod nefas est dicere». Portanto, quer em Deus (por natureza) quer nos anjos fiéis (por dom) coexistem sem contradição a libertas arbitrii e a impotentia peccandi.

Para tornar mais aceitável a tese, prima facie paradoxal, Anselmo avança com uma dicotomia: qual será a vontade que, de facto, se pode dizer mais livre: aquela que quer e pode não pecar - de tal modo que é capaz de não se deixar cair na sua recta resolução de não pecar - ou aquela que, de algum modo, pode deixar-se cair e pecar? É evidente, responde Anselmo, que «a que possui o que convém (quod decet), e que é vantajoso (quod expedit) de forma a não poder abandoná-lo, é mais livre que aquela que possui esse mesmo bem, mas de forma a poder perdê-lo e a ser susceptível de ser levada para o que é inconveniente (quod dedecet) e desvantajoso (non expedit).»

Numa palavra: é mais livre a que tem o querer e o poder que aquela que apenas quer mas não pode. Aqui ainda não aparece a relação directa da voluntas com a rectitudo, que será central no itinerário que Anselmo nos irá propor, mas aparece a noção de conveniência (quod decet), a qual traz já conexa consigo toda a estrutura metafísica do universo de Anselmo, indicando-nos que a questão da liberdade do arbítrio releva, em última instância, mais do plano ontológico que axiológico ${ }^{12}$.

A análise formal e eidética da vontade, porém, depara-se logo com uma objecção que o discipulus de Anselmo pretende fáctica: se assim é, como foi então que a natureza angélica e a natureza humana puderam pecar no início? Pelo que fica dito, parece não poder ter sido pela liberdade do arbitrio, visto que dela está excluído o posse peccare. Mas, então, se não foi de livre vontade que pecaram, como diremos que pecaram sponte, i.e., de seu grado? (Nam si sponte peccavit: quomodo non per liberum arbitri$u m$ ?) Não emergirá aqui então, ao lado ou em concorrência com o livre arbítrio, um qualquer poder estranho que compele a vontade a pecar?

É preciso distinguir para compreender, avisa Anselmo. Avança assim com uma nova afirmação também paradoxal: foi ao mesmo tempo pelo poder de pecar (potestas peccandi) e espontaneamente (sponte), pelo liberum arbitrium, e não por necessidade, que quer o anjo quer o homem

12 Cf. Risto SAARInen, The Weakness of the Will in the Medieval Tought. From Augustine to Buridan, Leiden, E. J. Brill, 1994, p. 44. Efectivamente, a concepção ontológica de conveniência é igualmente central no argumento do Proslogion, mostrando com clareza a insensatez do insensato que fere o princípio da não-contradição. Cf. a mesma noção no opúsculo mais directamente relacionado com o nosso tema: De Concordia praescientiae et praedestinationis et gratiae Dei cum libero arbitrio, in Complete Philosophical and Theological Treatises of Anselm of Canterbury (transl. By J. Hopkins \& H. Richardson), The Arthur J. Banning Press, Minneapolis, 2000. 
pecaram. «Foi por livre arbítrio que pecaram o anjo apóstata ou o primeiro homem, porque pecaram por seu arbítrio, que era livre a tal ponto que nada de diferente podia constrangê-la a pecar (nulla alia re cogi posset ad peccandum). E por isso foram justamente castigados: tendo liberdade de escolha, sem constrangimento, pecaram sponte. Pecaram pelo seu próprio arbítrio, que era livre, mas não por aquilo a partir de onde era livre (non per hoc unde liberum erat), i.e., não pelo poder que tinham de não pecar e de não se sujeitar ao pecado, mas pelo poder de pecar, o qual nem favorecia a liberdade para não pecar nem o obrigava à servidão do pecado.» ${ }^{13} \mathrm{E}$ se isto é válido para antes do primeiro pecado, é-o igualmente para depois do pecado, pois a potentia peccandi não pôde aniquilar a «liberdade natural de escolha» porque esta é inamissível.

Para nos fazer compreender o seu pensamento, Anselmo distingue aqui dois sentidos de potestas: um é poder interior da vontade como instrumento do querer (instrumentum volendi) em razão de si mesma, como poder elícito para a acção: voluntas propter se; outro é o uso desta vontade (usus sive opus volendi) ordenada exteriormente para a acção: voluntas propter aliud ${ }^{14}$. No texto esta distinção surge pela primeira vez pressuposta numa interrogação do Mestre ao Discípulo: «Por que razão (propter quid) é que a natureza racional devia guardar a rectidão: pela própria rectidão (an propter ipsam rectitudinem) ou por outra coisa (an propter aliud)?» ${ }^{15}$

$\mathrm{O}$ discípulo não tem dificuldade em responder e a liberdade do arbítrio vai, pois, ser definida a partir da sua causa final ${ }^{16}$, i.e., daquilo a que está naturalmente ordenada: a rectitudo do querer ${ }^{17}$. E a partir daqui o

13 De Libertate arbitrii, II, 210, 2-10: «Per liberum arbitrium peccauit apostata angelus siue primus homo, quia per suum arbitrium peccauit, quod sic liberum erat, $u t$ nulla alia re cogi posset ad peccandum. Et ideo iuste reprehenditur, quia cum hanc haberet arbitrii sui libertatem, non aliqua re cogente, non aliqua necessitate sed sponte peccauit. Peccauit autem per arbitrium suum quod erat liberum; sed non per hoc unde liberum erat, id est per potestatem qua poterat non peccare et peccato non seruire sed per potestatem quam habebat peccandi, qua nec ad non peccandi libertatem iuuabatur nec ad peccandi seruitutem cogebatur.»

14 Cf. De Libertate arbitrii, VII, 219, 12-16. R. SAARINEN, The Weakness of the Will..., p. 44, recorda a propósito a distinção estóica e agostiniana entre vontade actual e disposicional. Talvez possamos mesmo avançar com a distinção entre o plano transcendental da vontade (v.g., ao jeito de uma volonté voulante) e uma empírica da vontade (la volonté voulue).

15 De Libertate arbitrii, III, 212, 10-12: «Bene ad interrogata respondisti; sed adhuc opus est ut consideremus, propter quid illam rectitudinem seruare debebat rationalis natura: an propter ipsam rectitudinem, an propter aliud.»

16 Cf. Odon LotTIN, Psychologie et morale aux XIIe et XIIIe siècles. Tome I: Problèmes de Psychologie, J. Ducolot, Gembleaux, 1957, p. 13.

17 Cf. a 'rectitudo' como 'velle quod debet' também em De Veritate, IV, 181, 4-8: «Nam si, quamdiu voluit quod debuit, ad quod scilicet voluntatem acceperat, in rectitudine et in veritate fuit, et cum voluit quod non debuit, rectitudinem et verita- 
entendimento onto-teleológico da rectitudo determinará toda a pesquisa ulterior. Ora, aceitando-se que o poder de pecar (potestas peccandi) não pode entrar na definição da liberdade ${ }^{18}$, em que consiste, então, positivamente, de per si, a libertas arbitrii?

Responde Anselmo pela boca do Mestre: é o «poder de guardar a rectidão da vontade em razão da própria rectidão» - «potestas servandi rectitudinem voluntatis propter ipsam rectitudinem $\rangle^{19}$ - i.e., um poder que não está primeira e negativamente relacionado com o pecado (daí a afirmação de que o Abade do Bec perfilha um "optimismo antropológico", expressão que para alguns quer introduzir uma tensão com o Agostinho anti-pelagiano), mas antes directamente relacionado com a justiça original, pois a justiça é precisamente «a rectidão da vontade guardada por si mes$m a{ }^{20}$. Que consequências é que Anselmo quer tirar desta definição?

Antes de mais, quer mostrar-nos que, apesar do ser humano não ter conservado a rectidão quando o podia, i.e., quando a tinha na sua posse e podia 'facilmente' como refere no Proslogion, I: «(...) Porque não nos guardou ele, quando o podia facilmente, aquilo de que nos encontramos gravemente privados?»-, apesar disso (i.e., de não o ter guardado quando o podia) continua a ter em si o poder de reconhecer a verdade e a justiça e, ao mesmo tempo, o poder de as continuar a querer (ou não querer): não ficou nem cego para a primeira nem impotente para a segunda. Por outras palavras: mesmo na ausência (actual) da rectidão de vontade, a liberdade do arbítrio (propter se) continua a ter o poder de guardar aquilo que (já) não tem: pois «mesmo na ausência da rectidão de vontade, a natureza racional não tem menos o seu bem próprio» ${ }^{21}$. E este poder (potestas) nunca pôde ter sido perdido nem jamais pode sê-lo.

Por esta razão, nenhuma tentação, por mais forte que seja e por mais dificuldades que crie, pode levar o homem a pecar invitus, i.e., contra a sua vontade. Reza a este propósito um dos trechos mais célebres e decisivos de De Libertate arbitrii onde Anselmo defende a sinonímia de 'invitus' (contra sua vontade) com 'nolens' (sem querer):

tem deseruit: non aliud ibi potest intelligi veritas quam rectitudo, quoniam sive veritas sive rectitudo non aliud in eius voluntate fuit quam velle quod debuit.»

18 De Libertate arbitrii, I, 208, 11: «Denique nec libertas nem pars libertartis est potestas peccandi.»

19 De Libertate arbitrii, III, 212, 19-20, 22-23: «Illa libertas arbitrii est potestas servandi rectitudinem voluntatis propter ipsam rectitudinem»; «liberum arbitrium non esse aliud quam arbitrium potens servare rectitudinem voluntatis propter ipsam rectitudinem.»

20 De Libertate arbitrii, III, 212, 14-15: «Quoniam constat iustitiam esse rectitudinem voluntatis propter se servatam.»

21 De Libertate arbitrii, III, 212, 29-30: «Etiam si absit rectitudo voluntatis, non tamen rationalis natura minus habet quod suum est.» 
«Ninguém abandona [a rectidão da vontade] senão voluntariamente. Pois se 'invitus' quer dizer 'nolens', [então] ninguém a abandona 'invitus' (...). Com efeito, um homem pode ser atado [preso] contra a sua vontade, porque pode sê-lo sem o querer; pode ser torturado contra a sua vontade, porque pode sê-lo sem o querer; pode ser morto contra a sua vontade, porque pode sê-lo sem o querer. Mas não pode querer contra a sua vontade (invitus velle), porque não pode querer sem querer. Porque todo o homem que quer, quer precisamente o seu querer.» ${ }^{22}$

Apesar de esta passagem de De Libertate arbitrii refinar a argumentação de Santo Agostinho, no sentido de precisar claramente os limites do facere invitus próprio do homo duplex ${ }^{23}$, para o qual «querer e ser capaz de fazer não são o mesmo» ${ }^{24}$, ela não deixa de trazer à mente o que deve ter sido uma das leituras mais assíduas de Santo Anselmo: o De Libero arbitrio, onde Agostinho defende que se a vontade decaída não consegue querer directamente o seu bem próprio - pois se assim fosse, bastaria querer ser feliz para ser feliz, o que não se verifica, pois o querer é condição necessária mas não suficiente -, pode sempre querer querê-lo, e a possibilidade desta volição de segundo grau, auto-reflexiva, nunca pode deixar de estar em nosso poder ${ }^{25}$, mesmo depois do pecado, pois «nada

22 De Libertate arbitrii, V, 214, 18-23: « Nemo illam [rectitudinem voluntatis] deserit nisi volendo. Si ergo invitus dicitur nolens, nemo illam invitus. Ligari enim potest homo invitus, quia nolens potest ligari; torqueri potest invitus, quia nolens potest torqueri; occidi potest invitus, quia nolens potest occidi; velle autem non potest invitus quia velle non potest nolens velle. Nam omnis volens ipsum suum velle vult.» (itálico nosso)

23 Experiência de catividade da vontade que se encontrava já quer no Apóstolo Paulo $(\operatorname{Rm} 7,19)$ : «Non enim quod volo bonum hoc facio sed quod nolo malum hoc ago», quer no Poeta Ovídio (Metamorfoses, I, 20-21): «Video meliora proboque, deteriora sequor.»

24 Confessiones, VIII, 8, 20: «Tam multa ergo feci, ubi non hoc erat uelle quod posse.» Agostinho confessa alhures (Confessiones, VIII, 8, 20 - 9, 21, e note-se que é já depois de superado maniqueísmo) que tais contendas e discórdias da vontade consigo própria lhe despedaçaram a alma. V.g., VIII, 5, 10: «Da vontade pervertida nasce o desejo e, quando se obedece, nasce o hábito, e, quando se não resiste ao hábito, nasce a necessidade. Com estes como que pequenos elos ligados entre si - daí eu chamar-lhe 'cadeia' - mantinha-me preso a dura servidão. Pois a nova vontade, que eu começava a ter, a de te servir sem retribuição e querer fruir de ti, ó Deus, única alegria segura, ainda não era capaz de superar a primeira, consolidada como estava pelos muitos anos. Deste modo, estas minhas duas vontades, uma velha, outra nova, aquela carnal, esta espiritual, lutavam entre si e, opondo-se uma à outra, destroçavam-me a alma.»

25 R. SAARINEN, The Weakness of the Will..., p. 46: "Anselm here outlines a kind of "second-order will", that is a self-reflective will which has the actual or "first-order" will as its object. When Anselm concludes that "every one who wills, wills willingly" (omnis volens ipsum suum velle vult) he is saying that the second-order will must will what is willed by the first-order will. If we use the Holmström- 
está tão na vontade como a própria vontade.» ${ }^{26}$ Ela o único bem que não se perde sem que se queira perdê-lo ${ }^{27}$. A voluntas propter se é inamissí$\mathrm{vel}^{28}$ e destruí-la seria aniquilar o próprio homem (ou o anjo) qua talis.

Respondendo pois à pergunta inicial - «Se o homem tem sempre a liberdade do arbitrio?» - só podemos responder positivamente.

E o exemplo de alguém que mente invitus para salvar a sua vida, não contradiz a conclusão de que ninguém abandona invitus a rectidão da vontade. Porquê? De novo Anselmo socorre-se da distinção entre voluntas propter se e voluntas propter aliud. É que quando alguém mente com a finalidade de salvar a própria vida, não é a mentira que ele quer por si mesma em primeiro lugar, mas quere-a como que in obliquo et per accidens em razão de outra coisa (propter aliud), ou seja, salvar a sua vida. E sempre que isto acontece, quer dizer: sempre que alguém se encontra num dilema destes contra sua vontade, podemos dizer impropriamente que existem nele diversas vontades: diversas sunt voluntates ${ }^{29}$.

«Eis a razão pela qual ele mente invitus: quer seja morto ou minta invitus, é contra sua vontade (invitus) que se encontra neste dilema (in hac angustia) que implica necessariamente uma destas [contingên-

-Hintikka notation, this state affairs could be put as follows $\mathrm{W}(\mathrm{x}, \mathrm{p}) \rightarrow \mathrm{W}(\mathrm{x}, \mathrm{W}$ $(x, p)$ ). Let us call this "Anselm's principle", which is read as follows: "If $x$ wills that $\mathrm{p}$, then $\mathrm{x}$ wills that he wills that $\mathrm{p}$ ". "Will" here denotes an actual volition, i.e., a consent and not a mere desire.»

26 Agostinho de Hipona, De Libero arbitrio, I, 86: «Quid enim tam in voluntate quam ipsa voluntas sita est?»

27 Cf. Agostinho de Hipona, De Libero arbitrio, I, 83-85. V.g., «Parumne ergo gaudendum est habere nos quidam in animo, hanc ipsam dico bonam voluntatem, in cuius comparatione abiectissima sint ea quae commemoravimus, pro quibus adipiscendis multitudinem videmus hominum nullos labores, nulla pericula recusare?»

28 Santo Agostinho desenvolveu esta "dialéctica positiva da vontade" a partir de uma máxima de inspiração estóica que ele atribui a Terêncio: «Quoniam non potest id fieri quod vis, idvelis quod possis» (In Andria, Act.2, Scen.1). Múltiplas vezes refere Agostinho tal ideia: cf. De Beata Vita, IV, 25; De Trinitate, XIII, 7, 10; De Civitate Dei, XIV, 25; vide J. Cerqueira GONÇALVES, «La dialectique du vouloir et du pouvoir chez Saint Augustin (Résumé)», in Akten des XIV. Internationalem Kongresses für Philosophie, Wien. 2-9 Sptember 1968, Herder Wien, p. 474.

29 De Libertate arbitrii, V, 215, 5-6. Anselmo, parece-nos, quer dizer que, por vezes, podem existir em simultâneo volições com diferentes inclinações e finalidades que o agente não sabe como conciliar (v.g., viver e não-mentir), mas que em si mesmas não são inconciliáveis nem contraditórias. A oposição, porém, não esgota a gama de possibilidades. Em De Casu diaboli, 28, em De Concordia III, 11 e ainda nos Philosophical Fragments 25, 1 - 37, 6 (diferentes significações do verbo "facere"); 37, 29 - 39, 21 (diferentes significações de "velle, voluntas"; cons. em Complete Philosophical and Theological Treatises of Anselm of Canterbury (transl. By J. Hopkins \& H. Richardson), The Arthur J. Banning Press, Minneapolis, 2000), opera Anselmo uma mais fina fenomenologia do acto volitivo. 
cias]. ${ }^{30} \mathrm{O}$ que é necessário, o que não depende dele e é contra a sua vontade (invitus), é o facto de estar neste conflito, na situação de ter de escolher, mas não o resultado da escolha: «não é necessário mentir porque pode não mentir, se é morto. Nenhum destes desenlaces é determinado pela necessidade (neutrum enim est determinate in necessitate), porque um e outro estão em seu poder (quia utrumlibet est in potestate) $)^{31}$. Não há pois poder estranho algum que possa constranger o assentimento da vontade $^{32}$, e assim «perseverar na rectidão é vencer» ${ }^{33}$. «No homem o consentimento (consensum) da vontade, não acontece nem naturalmente (non naturaliter) nem por necessidade (ex necessitate), mas dá-se a partir de si mesma (ex se aperte videtur habere) $)^{34}$.

Mas não podemos esconder nem ignorar que existe na vontade uma certa impotência de que todos temos experiência aquando da tentação. Como conciliar aquele poder, que não se pode negar e que a análise mostrou, com esta impotência experimentada em perseverar até ao fim na manutenção da rectitudo ${ }^{35}$ Podemos dizer que, ex post facto, é difícil encontrar conciliação entre o poder de não pecar e a impotência experimentada; mas Anselmo coloca a questão a montante e aí o desfecho impõe-se necessariamente: mesmo no meio das maiores e mais fortes tentações, jamais podemos concluir que não podemos não querer o que elas nos sugerem. ${ }^{36}$ Acerca de um homem que 'quer' mentir para não morrer, não podemos dizer que lhe é impossível não querer mentir. «A vontade não é mais obrigada a querer a vida que a verdade.» ${ }^{37} \mathrm{~A}$ impotência aqui apenas quer dizer dificuldade, não uma condição inexorável da vontade. Por isso, a vontade é mais forte que a tentação, mesmo quando é vencida por ela!

Como explicar este paradoxo? Anselmo dá um exemplo elucidativo de modo a explicar a ambiguidade (aequivocatio) que se esconde sob o termo «voluntas» ${ }^{38}$ : uma coisa é a vontade que chamou instrumento do querer (instrumentum volendi) que é sempre uno e idêntico queira-se o que se quiser; mas a que é resultado desta, isto é, o seu uso e a sua obra

30 De Libertate arbitrii, V, 215,13-14: «Aut idcirco certe mentitur inuitus, quia inuitus aut occiditur aut mentitur, id est: inuitus est in hac angustia, ut ex necessitate unum horum quodlibet fiat.»

31 Cf. De Libertate arbitrii, V, 215, 17-18.

$32 \mathrm{Cf}$. De Libertate arbitrii, V, 216, 1.

33 De Libertate arbitrii, V, 216, 17: «Velle ipsam rectitudinem perserveranter est illi vincere.»

34 Cf. De Libertate arbitrii, V, 216, 8-12.

$35 \mathrm{Cf}$. De Libertate arbitrii, VI, 217, 10 e ss.

36 Cf. De Libertate arbitrii, VI, 217, 28-31.

37 De Libertate arbitrii, IX, 221, 21-22: «Non enim cogitur magis velle vitam quam veritatem».

38 Cf. De Libertate arbitrii, IV, 213, 27 - 214, 12; VII, 218, 24 - 220, 9. 
(usum sive opus eius) é tão múltiplo quanto numerosos e frequentes são os nossos quereres ${ }^{39}$. Assim, e para dar um símile facilmente compreensível, a vista (visus) é aquilo que nos permite orientar os olhos para coisas diferentes e ver; o resultado actual da vista é a visão (visio). Ora, mesmo nas trevas, com os olhos fechados ou vendados, continuamos a ter o poder de ver. Analogamente, o mesmo se passa com a vontade propter se, ainda quando propter aliud decaída.

Donde: «o que nos impede então de ter o poder de conservar a rectidão da vontade por si mesma, mesmo na sua ausência, quando temos em nós ao mesmo tempo a razão que nos permite reconhecê-la e a vontade que nos permite conservá-la? É nestas faculdades que consiste a dita liberdade do arbitrio.» ${ }^{40}$ Assim, a vontade, enquanto «instrumento do querer» possui uma força de decisão de que não pode nunca ser separada. Por isso, ainda e precisamente quando não resistiu e cedeu à tentação e abandonou a rectitudo, a vontade propter se pode continuar a querer não ter cedido e, portanto, tem a possibilidade de se converter para aquilo que quer ainda com maior força ${ }^{41}$.

E a este propósito, no capítulo VIII, Anselmo avança com a tese teologicamente mais ousada do opúsculo: apesar de poder reduzir a nada tudo aquilo que fez do nada (de nihilo), nem Deus pode retirar a rectidão a uma vontade que a possui. ${ }^{42}$ A explicação é clara: a rectidão da vontade, que permite qualificá-la como justa, é, como se disse, aquela que é guardada por si mesma, e não em vista de qualquer outra coisa. «Ora, não existe vontade justa, se não aquela que quer aquilo que Deus quer que ela queira.» ${ }^{43}$ Mas então, Deus para retirar à vontade a sua rectidão teria de querer. E assim, entraria em contradição com a noção de libertas arbitrii: ao retirar à vontade a rectitudo guardada por si mesma, Deus não quereria que a von-

39 De Libertate arbitrii, VII, 219, 12-16: «... voluntas, instrumentum scilicet volendi, semper est in anima, etiam cum non vult aliquid, velut cum dormit; voluntatem vero quam dico usum sive opus eiusdem instrumenti, non habemus nisi quando volumus aliquid. Illa sempre igitur voluntas quam voco instrumentum volendi, una et eadem semper est quidquid velimus: illa vero quae opus eius est, tam multiplex est quam multa et quam saepe volumus.»

40 De Libertate arbitrii, IV, 214, 4-7: «Quid prohibit nos habere potestatem servandi rectitudinem, quamdiu et ratio in nobis est qua eam valemus cognoscere, et voluntas qua illam tenere possumus? Ex His enim constat praefata libertas arbitrii.»

41 De Libertate arbitrii, VII, 220, 8-9: «Vides igitur quia cum homo habitam rectitudinem voluntatis aliqua ingruente deserit tentatione, nulla vi aliena abstrahitur, sed ipsa se convertit ad id quod fortius vult.» (itálico nosso)

42 De Libertate arbitrii, VIII, 220, 13-15: «Totam substantiam quam de nihilo fecit, potest redigere in nihilum, a voluntate vero habente rectitudinem non valet illam separare.» Cf. M. Corbin, «De l'impossible en Dieu», in Revue de sciences philosophiques et théologiques (1982), pp. 523-550.

43 De Libertate arbitrii, VIII, 220, 18-19: «Nulla autem est iusta voluntas, nisi quae vult quod Deus vult illam velle.» 
tade quisesse aquilo que Ele quer que ela queira, o que é absolutamente impossível ${ }^{44}$. Nada, pois, pode ser mais livre que uma vontade recta ${ }^{45}$.

E se lhe acontece de facto (propter aliud) perder a rectidão? É verdade que fica serva do pecado e já não pode recuperar a rectitudo por si só; mas nem assim, em razão de tal servidão, perde a liberdade de escolha, ou seja, de arbítrio. A propensão "intelectualista" 46 de Anselmo fá-lo concluir que, mesmo quando nos falta a rectidão da vontade, continuamos a ter a aptidão para compreender e querer o que nos permite guardá-la por si mesma (ainda quando a não temos).

Assim, o homem tem sempre em sua mão o poder de guardar a rectidão, tanto quando a tem como quando a não tem. Por esta razão é sempre elicitamente livre ${ }^{47}$, mesmo quando não consiga fazer uso imperado dessa liberdade. «Do pecado e servidão só pode voltar por [graça ${ }^{48}$ de outro; da rectidão só pode decair por si mesmo. Mas da sua liberdade não pode ser desapossado nem por si nem por outro. Por natureza, o homem é sempre livre de guardar a rectidão, se a tem, e [continua livre] mesmo também quando já não a tem para a guardar» ${ }^{49}$.

Donde, reitera Anselmo, que a mais correcta definição de libertas arbitrii seja o «poder de guardar a rectidão da vontade em razão da própria rectidão» ${ }^{50}$, e tal potestas, sem contradição, não pode compreender o poder de pecar.

44 De Libertate arbitrii, VIII, 221, 8-9: «Igitur nihil magis impossibile, quam deum rectitudinem voluntatis auferre.» Note-se o paralelo com o modo de argumentar a favor da existência de Deus in mente e in re do Proslogion, II: «Si ergo id quo majus cogitari non potest, est in solo intellectu, idipsum, quo majus cogitari non potest, est quo majus cogitari potest: sed certe hoc esse non potest.» (itálico nosso) Em ambos os casos a conclusão é retirada a partir do princípio da identidade (conveniência) e do princípio da não-contradição: Proslogion, III: «quod convenire non potest.»

45 Cf. De Libertate arbitrii, IX, 221, 17: «Quod nihil sit liberius recta voluntate.»

46 Cf. Risto SAARINEN, The Weakness of the Will..., p. 45: «Anselm's view is "intellectualistic" in the sense that free will always serves rational uprightness. He thus defends the ideia that man is essentially a rational being and rejects the idea that free will can debilerately choose to do wrong.» Esta afirmação de "intelectualista", que pretensamente coloca Anselmo como "precursor" da Escolástica posterior e de Tomás de Aquino, é discutida e recusada por Michel Corbin na Introdução a De Libertate arbitrii, pp. 181-202.

47 De Libertate arbitrii, XII, 224, 3-5: «Potestatem autem servandi rectitudinem semper habet, et cum rectitudinem habet et cum non habet; et ideo semper liber est.»

48 De Libertate arbitrii abre aqui a porta a Cur Deus homo.

49 De Libertate arbitrii, XI, 223, 9-11: «... et a libertate sua nec per se nec per alium potest privari. Semper enim naturaliter liber est ad servandum rectitudinem si eam habet, etiam quando quam servet non habet.» (itálico nosso)

50 De Libertate arbitrii, XIII, 225, 2-3: «Quod 'potestas servandi rectitudinem voluntatis propter ipsam rectitudinem' sit perfecta definitio libertatis arbitrii». 


\section{RESUMO}

O liberum arbitrium, para Santo Anselmo, não pode residir no poder permanente de pecar e de não pecar (posse peccare et non peccare), porque tal definição tornaria inútil «a graça, a predestinação e a presciência de Deus» ( $D L A, \mathrm{I}$, 207, 1-2). Por outro lado, se nós não tivéssemos sempre essa potestas, o pecado não poderia ser-nos imputado porque nós pecaríamos «sine libero arbitrio».

Procurando separar esta alternativa, que lhe parece armadilhada, Santo Anselmo busca uma definição de libertas arbitrii independente do poder negativo de pecar (potestas peccandi) e, a partir da distinção entre voluntas propter se (instrumentum volendi) e voluntas propter aliud (usus sive opus volendi), julga encontrá-la na seguinte: a libertas arbitrii é «o poder de guardar a rectitude da vontade pela própria rectitude» (DLA, III, 212, 19-20: «potestas servandi rectitudinem voluntatis propter ipsam rectitudinem»), poder que exprime a exacta e positiva noção da «justiça original». À luz de tal definição transcendental de libertas arbitrii, comum a Deus, aos anjos e aos homens, pode Anselmo avançar a tese teologicamente mais ousada do opúsculo: nem Deus, apesar de poder «reduzir a nada uma substância que Ele fez do nada», é capaz de «separar a rectidão de uma vontade que a possui» (DLA, VIII, 220, 13-15).

\section{RESUME}

Le liberum arbitrium, pour saint Anselme, ne peut pas résider dans le pouvoir permanent de pécher et ne pas pécher (posse peccare et non peccare), parce que telle définition rendrait inutile «la grâce, la prédestination et la prescience de Dieu» (DLA, I, 207, 1-2). D'autre côté, si nous n'eussions pas toujours cette potestas, alors le péché ne pourrait pas nous être imputé parce que nous pécherions «sine libero arbitrio».

En cherchant trancher cette alternative, que lui semble piégée, saint Anselme demande une définition de libertas arbitrii indépendente du pouvoir négatif de pécher (potestas peccandi) et, d'après la distinction entre voluntas propter se (instrumentum volendi) et voluntas propter aliud (usus sive opus volendi), croit la trouver dans la suivante: la libertas arbitrii c'est «le pouvoir de garder la droiture de volonté pour la droiture elle-même» (DLA, III, 212, 19-20: «potestas servandi rectitudinem voluntatis propter ipsam rectitudinem»), pouvoir qu'exprime l'exacte et positive notion de la «justice originelle». À la lumière de telle définition de libertas arbitrii transcendantale, commune à Dieu, aux anges et aux hommes, peut Anselme avancer la thèse théologiquement plus hardie de l'opuscule: ni Dieu, malgré pouvoir «réduire à rien une substance qu'Il a faite de rien», est capable «de retrancher la droiture à une volonté qui la possède» ( $D L A$, VIII, 220, 13-15). 